\title{
Seroprevalence of Hepatitis C, Hepatitis B, Cytomegalovirus, and Human Immunodeficiency Viruses in Multitransfused Thalassemic Children in Upper Egypt
}

\author{
Ramadan A. Mahmoud, ${ }^{1}$ Abdel-Azeem M. El-Mazary, ${ }^{2}$ and Ashraf Khodeary ${ }^{3}$ \\ ${ }^{1}$ Department of Pediatrics, Faculty of Medicine, Sohag University, Sohag 82524, Egypt \\ ${ }^{2}$ Department of Pediatrics, Faculty of Medicine, Minia University, Minia 61111, Egypt \\ ${ }^{3}$ Department of Clinical Pathology, Faculty of Medicine, Sohag University, Sohag 82524, Egypt \\ Correspondence should be addressed to Ramadan A. Mahmoud; ramadan.aboelhassan@yahoo.com
}

Received 20 November 2015; Accepted 26 January 2016

Academic Editor: Meral Beksac

Copyright ( 2016 Ramadan A. Mahmoud et al. This is an open access article distributed under the Creative Commons Attribution License, which permits unrestricted use, distribution, and reproduction in any medium, provided the original work is properly cited.

Background. Frequent blood transfusions in thalassemia major children expose them to the risk of transfusion-transmitted infections (TTIs). The aim of this study was to estimate the prevalence of hepatitis $\mathrm{C}$ virus (HCV), hepatitis B virus (HBV), human immunodeficiency virus (HIV), and cytomegalovirus (CMV) in thalassemic children attending the Pediatrics Departments of both Sohag and Minia Universities of Upper Egypt, during the period from May 2014 to May 2015. Methods. Serum samples were screened for hepatitis B surface antigen (HBsAg), anti-HCV, anti-CMV, and anti-HIV type 1 and type 2 using the Vitek Immunodiagnostic Assay System. Results. The frequencies of anti-HCV, HBsAg, anti-CMV, and anti-HIV type 1 and type 2 were found to be 37.11\%, $4.12 \%, 4.12 \%, 0.00 \%$, and $0.00 \%$, respectively. Seropositivity for anti-HCV, HBsAg, and anti-CMV increased with increasing age of the patients, duration of the disease, serum ferritin level $(\mathrm{ng} / \mathrm{mL})$, and liver enzymes $(\mathrm{U} / \mathrm{L})$, while it was not significantly associated with gender, frequency of blood transfusion, or the status of splenectomy operation $(P>0.05)$. Conclusion. The frequency of TTIs, especially HCV, is considerably high among Egyptian children with thalassemia major. It is therefore important to implement measures to improve blood transfusion screening, such as polymerase chain reaction, in order to reduce TTIs from blood donor units.

\section{Introduction}

Thalassemias are the commonest monogenic disorders in the world [1], and the incidence rate is higher in the Middle East [2]. $\beta$-thalassemia constitutes a major health problem in Egypt with an estimated carrier rate of 9-10\% [3]. It is an autosomal recessive disorder of hemoglobin synthesis caused by a direct downregulation in the synthesis of structurally normal $\beta$-globin chains. Due to the excess $\alpha$-globin chains relative to the $\beta$-globin chains, $\alpha$-globin tetramers $(\alpha 4)$ are formed and interact with the red cell membrane, leading to hemolytic anemia and increased erythroid production [4].

Survival of the patients mainly depends upon regular blood transfusions, which may lead to further complications, such as absorptive iron overload and transfusion-transmitted infections (TTIs), and this may contribute to the morbidity and mortality of patients with thalassemia major [5].

Screening of donor blood through national protocols for possible infections, including hepatitis B virus (HBV), hepatitis $\mathrm{C}$ virus (HCV), cytomegalovirus (CMV), and human immunodeficiency virus (HIV), is considered the optimal preventive method. There is a constant need to explore the effect of currently used protocols of blood donor screening by determining the burden of TTIs in multitransfused patients [6].

In Egypt the lack of a central surveillance system for disease epidemiology is a major obstacle regarding the assessment of the current situation of infectious diseases, including TTIs, and, therefore, regional and periodic studies are the only option to monitor recent developments. There are only 
a few studies about TTIs in thalassemic children in Egypt [3, 7-9]. To our knowledge, no study has described the situation of TTIs in thalassemic children in Upper Egypt. These areas had low social economic income compared to other parts in Egypt [10]. The objective of this study was to evaluate the seroprevalence of HBV, HCV, CMV, and HIV. Furthermore, TTI-associated clinical and laboratory risk factors were investigated in this study including gender, family history, duration of the illness, frequency of blood transfusions, splenectomy, hemoglobin, ferritin level, creatinine levels, and liver enzymes.

\section{Materials and Methods}

In this cross-sectional study, we analyzed blood samples taken from 97 transfusion-dependent thalassemic children during the period from May 2014 to May 2015 in the Pediatrics Departments, Faculty of Medicine, in both Sohag and Minia Universities of Upper Egypt. Ethical approval for the study was obtained from the Research Committee of the Medical Faculty, Sohag and Minia Universities, and written informed consents were obtained from all guardians/parents of the children prior to data and sample collection.

Inclusion criteria included all known cases of $\beta$-thalassemia major according to hemoglobin electrophoresis data. Complete information regarding clinical profile and family history of patients was also mandatory for inclusion criteria.

Hemophilic children, as well as children with other types of hemolytic anemias, such as $\alpha$-thalassemia, sickle cell anemia, and spherocytosis were excluded from the study.

Thalassemic children were subjected to a detailed history and thorough clinical examination. Special emphasis was given on personal history (age, gender, and location), family history (parent consanguinity, and family history of similar conditions), clinical data (age of diagnosis and number of blood transfusions), and clinical examination (pallor, jaundice, hepatomegaly, cirrhotic manifestations, splenomegaly, splenectomy, and murmur on the heart) and laboratory data (hemoglobin, serum ferritin levels, serum creatinine, and liver enzymes) were recorded.

For laboratory assessments, $7 \mathrm{mLs}$ of blood was obtained by venipuncture with strict sterile measures into a sterile plane tube and pediatric EDTA vacationer tube. In children receiving blood transfusions, samples were drawn before packed-RBC transfusion. Serum was collected in two tubes: one for serological testing and the other for the HCV-RTPCR. The serum was kept at $-20^{\circ} \mathrm{C}$ until the time of the assay.

For the serological tests, $\mathrm{HBsAg}, \mathrm{HCV}$ antibodies, CMV IgM antibodies, and HIV type 1 and type 2 antibodies were measured by the Vitek Immunodiagnostic Assay System (VIDAS-BioMerieux, France) which is an enzyme-linked fluorescent assay, and it was performed according to the manufacturer's instructions. Briefly, the instrument uses a disposable pipette tip called the solid-phase receptacle, which is coated with antigens and also acts as a pipetting device. All the ready-to-use reagents are contained in a sealed strip. The specimen (serum or plasma) is added to the reagent strip, and all the following steps of the test are done automatically, without any further manipulation.
The positive HCV cases were confirmed and tested for viral load by reverse transcriptase polymerase chain reaction (RT-PCR) [11]. RNA extraction was carried out using the Qiagen RNA extraction kit according to the kit manual. PCR was performed using the Applied Biosystems ${ }^{\circledast}$ TaqMan $^{\circledR}$ Universal PCR master mix and the Applied Biosystems StepOne ${ }^{\text {TM }}$ Real-Time PCR System according to the manufacturer's instructions.

A complete blood count (CBC) was performed with all samples using a Celtic autocounter after calibration. Pretransfusion samples were considered for patients requiring blood transfusions at the time of study. Serum ferritin levels, alanine transaminase level (ALT), aspartate aminotransferase (AST), and creatinine levels were measured using VIDAS.

2.1. Statistical Analysis. Data was analyzed using SPSS (Statistical Package of Social Science) version 16. Quantitative data are represented as the mean (standard deviation) or median (range). Data were analyzed using the Mann-Whitney test as they were not normally distributed. Qualitative data are presented as number and percentage and were compared using either the Chi-square test or the Fisher exact test. Graphs were produced using Excel software. The $P$ value was considered significant at $P<0.05$.

\section{Results}

In the study with a total of 97 thalassemic children, $36.08 \%$ of patients were female and $63.92 \%$ were male. The mean age at the time of study was 8.89 (5.07) years (range: 6-18 years). The mean age at diagnosis was 11.40 (13.18) months. The mean duration of the disease was 7.94 (4.90) years. The mean ferritin level was 2875 (1764) (ng/mL). Complete history and clinical examination was done for all the children included in the study as shown in Table 1.

A total of 36 patients $(37.11 \%)$ were found to be anti-HCV antibody- (anti-HCV-) positive (Table 2). All positive cases were confirmed by HCV-RT-PCR. There were only 4 (4.12\%) patients that were found to be positive for HBsAg and antiCMV IgM. There were no cases that were positive for antiHIV type 1 or type 2 . Three patients had two infectious diseases simultaneously (two had HBV and HCV, and one had HCV and CMV).

The risk factors for hepatitis $\mathrm{C}$ virus are shown in Table 3 and include age of the patients [7.69 (5.01) years in negative cases compared to $12.63(4.96)$ years in positive cases $(P=$ $0.04)$ ], mean ferritin level [2416 (1283) $\mathrm{ng} / \mathrm{mL}$ in negative cases compared to $3652(2173) \mathrm{ng} / \mathrm{mL}$ in positive cases $(P=$ 0.006)], serum ALT [48 (7.4) U/L in negative cases compared to $65(5.1) \mathrm{U} / \mathrm{L}$ in positive cases $(P=0.001)]$, serum AST [47 (9.44) U/L in negative cases compared to 61 (8.9) U/L in positive cases $(P=0.02)]$, and duration of the disease [7.75 $(4.62)$ years in negative cases compared to 10.56 (5.48) years for positive cases $(P=0.02)]$. With a total of 97 patients included in the study there were 6 patients $(6.18 \%)$ who had manifestations of liver cirrhosis, two were HBV and HCV positive, two were HCV positive, and two were serologically free of viruses.

For hepatitis B virus infection, risk factors are shown in Table 4 and included the age of patients [7.77 (4.08\%) years 
TABLE 1: Demographic characteristics of beta thalassemia major children.

\begin{tabular}{|c|c|c|}
\hline Characteristics & & Summary statistics \\
\hline \multirow{2}{*}{ Age/years } & Mean (SD) & $8.89(5.07)$ \\
\hline & Median (range) & $10(6-18)$ \\
\hline \multirow{2}{*}{ Gender } & Females & $35(36.08 \%)$ \\
\hline & Males & $62(63.92 \%)$ \\
\hline \multirow{2}{*}{ Age at diagnosis/months } & Mean (SD) & $11.40(13.18)$ \\
\hline & Median (range) & $6(3-72)$ \\
\hline Frequency of blood transfusion/months & Mean (SD) & $1.09(0.42)$ \\
\hline Duration of disease/years & Mean (SD) & $7.94(4.90)$ \\
\hline \multirow{2}{*}{ Family history } & No & $42(43.30 \%)$ \\
\hline & Yes & $55(56.70 \%)$ \\
\hline Ferritin level (ng/mL) & Mean (SD) & $2875(1764)$ \\
\hline Alanine transaminase (ALT) (U/L) & Mean (SD) & $55(15.4)$ \\
\hline Aspartate aminotransferase (AST) (U/L) & Mean (SD) & $62(9.44)$ \\
\hline Creatinine $(\mathrm{mg} / \mathrm{dL})$ & Mean (SD) & $0.6(0.54)$ \\
\hline Hb level $(\mathrm{g} / \mathrm{dL})$ & Mean (SD) & $6.77(1.87)$ \\
\hline \multirow{2}{*}{ Hepatomegaly } & No & $9(9.27 \%)$ \\
\hline & Yes & $88(90.73 \%)$ \\
\hline \multirow{2}{*}{ Splenomegaly } & No & $3(3.09 \%)$ \\
\hline & Yes & $94(96.9 \%)$ \\
\hline \multirow{2}{*}{ Splenectomy } & No & $56(57.73 \%)$ \\
\hline & Yes & $41(42.27 \%)$ \\
\hline Age at splenectomy/years & Mean (SD) & $8.39(2.47)$ \\
\hline \multirow{2}{*}{ Pallor } & No & $11(11.34 \%)$ \\
\hline & Yes & $86(88.66 \%)$ \\
\hline \multirow{2}{*}{ Jaundice } & No & $80(82.47 \%)$ \\
\hline & Yes & $17(17.53 \%)$ \\
\hline \multirow{2}{*}{ Murmur } & No & $56(57.73 \%)$ \\
\hline & Yes & $41(42.27 \%)$ \\
\hline
\end{tabular}

TABLE 2: Prevalence of transfusion transmitted infections (TTIs) in thalassemic children.

\begin{tabular}{lcc}
\hline $\begin{array}{l}\text { Transfusion transmitted } \\
\text { infections (TTIs) }\end{array}$ & & Numbers (percentage) \\
\hline Hepatitis C virus & Negative & $61(62.89 \%)$ \\
& Positive & $36(37.11 \%)$ \\
\hline \multirow{2}{*}{ Hepatitis B virus } & Negative & $93(95.88 \%)$ \\
& Positive & $4(4.12 \%)$ \\
\hline CMV & Negative & $93(95.88 \%)$ \\
& Positive & $4(4.12 \%)$ \\
\hline HIV & Negative & $97(100 \%)$ \\
\hline
\end{tabular}

in negative cases compared to 13.5 (1.73) years in positive cases $(P=0.04)]$, mean ferritin level $[2809(1750) \mathrm{ng} / \mathrm{mL}$ in negative cases compared to 4407 (1541) $\mathrm{ng} / \mathrm{mL}$ in positive cases $(P=0.04)]$, serum ALT [43 (4.4) U/L in negative cases compared to $58(3.5) \mathrm{U} / \mathrm{L}$ in positive cases $(P=0.03)]$, serum AST [42 (9.44) U/L in negative cases compared to 63
(6.3) $\mathrm{U} / \mathrm{L}$ in positive cases $(P=0.04)]$, and duration of the disease [7.71 (4.86) years in negative cases compared to 13.25 (1.73) years in positive cases $(P=0.02)]$.

CMV risk factors are shown in Table 5 and include age of the patients [8.69 (6.01) years in negative cases compared to $13.63(4.21)$ years in positive cases $(P=0.03)]$, mean ferritin level [2894 (1770) $\mathrm{ng} / \mathrm{mL}$ in negative cases compared to $4735(1789) \mathrm{ng} / \mathrm{mL}$ in positive cases $(P=0.04)]$, and mean duration of the disease [7.82 (4.92) years in negative cases compared to 13.69 (3.79) years in positive cases $(P=0.03)$ ]. The distribution of disease status (thalassemia and hepatitis $B$, hepatitis C, CMV, and HIV) was not significantly associated with gender, frequency of blood transfusion, hemoglobin level, creatinine level, or splenectomy operations $(P>0.05)$.

\section{Discussion}

Thalassemia major is one of the most common autosomal single-gene thalassemic disorders. It is prevalent in more than 60 countries of the world with a carrier population of up to 150 million worldwide [12]. In order to reduce the complications of severe anemia in $\beta$-thalassemic patients, 
TABLE 3: Risk factors for HCV.

\begin{tabular}{|c|c|c|c|c|}
\hline \multirow{2}{*}{ Risk factors } & & \multicolumn{2}{|c|}{$\mathrm{HCV}$} & \multirow{2}{*}{$P$ value* } \\
\hline & & No $(n=61)$ & Yes $(n=36)$ & \\
\hline \multirow{2}{*}{ Age/years } & Mean (SD) & $7.69(5.01)$ & $12.63(4.96)$ & \multirow{2}{*}{0.04} \\
\hline & Median (range) & $9(1-19)$ & $14(6.5-18)$ & \\
\hline \multirow{2}{*}{ Gender } & Females & $26(42.62 \%)$ & $9(25.00 \%)$ & \multirow{2}{*}{0.08} \\
\hline & Males & $35(57.38 \%)$ & $27(75.00 \%)$ & \\
\hline Duration of the disease/years & Mean (SD) & $7.75(4.62)$ & $10.56(5.48)$ & 0.02 \\
\hline Frequency of blood transfusion/months & Mean (SD) & $1.11(0.48)$ & $1.04(0.30)$ & 0.57 \\
\hline \multirow{2}{*}{ Splenectomy } & No & $36(59.02 \%)$ & $20(55.56 \%)$ & \multirow{2}{*}{0.74} \\
\hline & Yes & $25(40.98 \%)$ & $16(44.44 \%)$ & \\
\hline Ferritin level (ng/dL) & Mean (SD) & $2416(1283)$ & $3652(2173)$ & 0.006 \\
\hline Alanine transaminase (ALT) (U/L) & Mean (SD) & $48(7.4)$ & $65(5.1)$ & 0.001 \\
\hline Aspartate aminotransferase (AST) (U/L) & Mean $(\mathrm{SD})$ & $47(9.44)$ & $61(8.9)$ & 0.02 \\
\hline
\end{tabular}

${ }^{*} P$ values were obtained by using Mann-Whitney test or Chi-square test.

TABLE 4: Risk factors for HBV.

\begin{tabular}{|c|c|c|c|c|}
\hline \multirow{2}{*}{ Risk factors } & & \multicolumn{2}{|c|}{$\mathrm{HBV}$} & \multirow{2}{*}{$P$ value* } \\
\hline & & No $(n=93)$ & Yes $(n=4)$ & \\
\hline \multirow{2}{*}{ Age/years } & Mean (SD) & $7.77(4.08 \%)$ & $13.5(1.73)$ & \multirow{2}{*}{0.04} \\
\hline & Median (range) & $8(1-20)$ & $13.5(12-15)$ & \\
\hline \multirow{2}{*}{ Gender } & Females & $34(36.56 \%)$ & $1(25.00 \%)$ & \multirow{2}{*}{0.08} \\
\hline & Males & $59(63.44 \%)$ & $3(75.00 \%)$ & \\
\hline Duration of the disease/years & Mean (SD) & $7.71(4.86)$ & $13.25(1.73)$ & 0.02 \\
\hline Frequency of blood transfusion/months & Mean (SD) & $1.09(0.43)$ & $1(0)$ & 0.77 \\
\hline \multirow{2}{*}{ Splenectomy } & No & $56(60.22 \%)$ & $2(50 \%)$ & \multirow{2}{*}{1.00} \\
\hline & Yes & $37(39.78 \%)$ & $2(50 \%)$ & \\
\hline Ferritin level (ng/dL) & Mean (SD) & $2809(1750)$ & 4407 (1541) & 0.04 \\
\hline Alanine transaminase (ALT) (U/L) & Mean (SD) & $43(4.4)$ & $58(3.5)$ & 0.03 \\
\hline Aspartate aminotransferase (AST) (U/L) & Mean (SD) & $42(9.44)$ & $63(6.3)$ & 0.04 \\
\hline
\end{tabular}

${ }^{*} P$ values were obtained by using Mann-Whitney test or Chi-square test percentage.

early and regular blood transfusion therapy is mandatory. Thalassemic patients had a risk for iron overload and for TTIs, such as HBV, HCV, CMV, and HIV [13]. The current study focuses on the prevalence of these viruses in children attending the Pediatrics Departments of both Sohag and Minia Universities of Upper Egypt.

In Egypt, the screening tests for the blood donors include $\mathrm{HCV}$ antibodies, HBsAg, and HIV antibodies. Moreover, in the 2000 some blood bank added CMV antibody and syphilis antibodies to the blood donor screening [8]. These tests were done by ELISA or immunofluorescence based methods in national and governmental blood banks which have high sensitivity and specificity [14]. However, many nongovernmental and private hospitals sometimes used rapid and cheap immunochromatographic methods for blood donors screening which have lower sensitivity and specificity, which contribute to the increased rates of TTIs [15]. Furthermore, the diagnosis of viral hepatitis in the window phase is still an obstacle in Egypt, because of Egypt's constrained economy which limits the implementation of sensitive screening techniques as RT-PCR for all cases [16].
Egypt has one of the highest prevalence rates of the virus in the world; an estimated $10-15 \%$ of the population, about 8-10 million people, is carrying hepatitis $\mathrm{C}$ antibodies. Five million of those are actively infected. The iatrogenic role of parenteral antischistosomal therapy campaigns carried out until the 1980s may have contributed to such high incidence of HCV. Sharing razors, piercing, and tattooing were also suggested as possible explanations [17].

The implementation of routine blood donor screening tests for HCV in the early 1990s led to a reduction in the transfusion of HCV to blood recipients [18], from about 70\% in one cohort study [19] to $37 \%$ in this present study. Furthermore, the introduction of advanced screening methods, such as RT-PCR, has led to a further decline in transfusion-related viral hepatitis [11]. RT-PCR technologies can detect viremia earlier than the existing screening tests. Blood centers in some developed countries as the United States have implemented RT-PCR routinely for all blood donations since 1999. This strategy has reduced the window period for HCV detection by 50-60 days and decreased the risk for HCV transmission from 1 in 103,000 to 1 in 2,000,000 transfused units [20]. 
TABLE 5: Risk factors for CMV.

\begin{tabular}{|c|c|c|c|c|}
\hline \multirow{2}{*}{ Risk factors } & & \multicolumn{2}{|c|}{ CMV } & \multirow{2}{*}{$P$ value* } \\
\hline & & No $(n=93)$ & Yes $(n=4)$ & \\
\hline \multirow{2}{*}{ Age/years } & Mean (SD) & $8.69(6.01)$ & $13.63(4.21)$ & \multirow{2}{*}{0.03} \\
\hline & Median (range) & $10(1-21)$ & $15(6.5-18)$ & \\
\hline \multirow{2}{*}{ Gender } & Females & $32(34.41 \%)$ & $3(75.00 \%)$ & \multirow{2}{*}{0.14} \\
\hline & Males & $61(65.59 \%)$ & $1(25.00 \%)$ & \\
\hline Duration of the disease/years & Mean (SD) & $7.82(4.92)$ & $13.69(3.79)$ & 0.03 \\
\hline Frequency of blood transfusion/months & Mean (SD) & $1.09(0.43)$ & $0.88(0.25)$ & 0.21 \\
\hline \multirow{2}{*}{ Splenectomy } & No & $55(59.14 \%)$ & $1(25.00 \%)$ & \multirow{2}{*}{0.31} \\
\hline & Yes & $38(40.86 \%)$ & $3(75.00 \%)$ & \\
\hline Ferritin level (ng/dL) & Mean (SD) & $2894(1770)$ & $4735(1789)$ & 0.04 \\
\hline Alanine transaminase (ALT) (U/L) & Mean (SD) & $55(3.4)$ & $56(3.7)$ & 0.43 \\
\hline Aspartate aminotransferase (AST) (U/L) & Mean (SD) & $50(6.44)$ & $54(6.8)$ & 0.14 \\
\hline
\end{tabular}

${ }^{*} P$ values were obtained by using Mann-Whitney test, Chi-square test, or Fisher exact test.

However, despite these efforts, posttransfusion transmission of HCV has remained a major health problem in multitransfused patients, leading to increased morbidity and mortality. In the present study, more than $37 \%$ of patients were positive for anti-HCV. These results can be compared with previously conducted studies from other regions of Egypt, such as anti-HCV in one Egyptian report of about 34\% [7], and in another study of about $24 \%$ [8]. Moreover, in other countries, anti-HCV-positive cases were about $40.5 \%$ in Jordan [21], 30\% in India [22], and 35\% in Pakistan [23].

Furthermore, the severity of liver cirrhosis due to HCV in patients with thalassemia may be greater because of concomitant iron overload. It has been demonstrated that iron and HCV infection are independent but mutually reinforcing risk factors for the development of liver fibrosis and cirrhosis. It appears therefore that patients with thalassemia, particularly those with poor control of iron overload, face an increased risk of developing cirrhosis [24].

In the present study, four patients were HCV positive and had manifestations of liver cirrhosis. Ardalan et al. found that the rate of liver fibrosis accelerated in patients with iron overload and HCV when compared to patients with thalassemia major alone [25]. Moreover, Zurlo et al. found that advanced liver fibrosis is one of the most common causes of death in transfusion-dependent thalassemia patients over 15 years old [26].

Children with thalassemia major are particularly susceptible to HBV because they receive multiple blood transfusions. These children have higher infection rates than normal children. Egypt has adopted a universal hepatitis B vaccine service for infants since 1992. The primary objective of vaccination is to eliminate chronic HBV infections and ultimately reduce the reservoir for new infections [17]. In the present study, about $4 \%$ were positive for HBV, and in another Egyptian study [8], about 3\% were positive for HBV. These results were slightly higher than a recent North Indian study, in which out of the 462 thalassemic children 13 cases (2.8\%) were positive for HBsAg by ELISA [27], and also higher than an Iranian study in which only $1.5 \%$ were $\mathrm{HBsAg}$ positive [28].
Screening in most Egyptian blood banks is performed for HBsAg but not for core antibody (anti-HBc). Anti-HBc appears at the onset of acute HBV infection and may also indicate chronic infection. The routine implementation of anti-HBc testing was recommended to reduce the risk of transfusion-transmitted HBV. In a previous Egyptian study, $7.8 \%$ of blood samples were anti-HBc positive, of which $6.25 \%$ were HBV DNA positive [29]. In another Egyptian study by Said et al., they found that the prevalence of anti- $\mathrm{HBc}$ among HBsAg negative blood donors was 14.2\% [30]. Furthermore, $\mathrm{HBV}$ can also be transmitted through components that are HBsAg negative but HBV DNA positive. Altindis et al. recommended routine screening of blood units by sensitive PCRbased methods, to detect possible occult HBV infections [31].

For CMV, only $4 \%$ of thalassemic patients were CMV positive, and these results were slightly higher than the Jamal et al. study in Malaysia [32], which found that the incidence of CMV was about $1.8 \%$. Transfusion-transmitted HIV is, fortunately, not a major cause for concern, owing to advanced testing techniques, such as the recent generation of ELISA screening tests, as well as decreasing prevalence of such diseases, which is less than $0.02 \%$ in Egyptian population [33], conservative culture, and increasing awareness about this infection in the general population. Therefore, in this study, we did not find any positive cases for HIV type 1 or type 2. These results corroborate other studies $[28,32]$ that also found no positive cases for HIV in thalassemic patients. Nevertheless, an Indian study found that the seroprevalence of HIV was about $1.5 \%$ [34].

As shown in the present study, patients with thalassemia have a high prevalence of hepatitis $B$ and hepatitis $C$ infections. Furthermore, HCV and HBV infected patients had significantly higher liver enzymes than noninfected patients. Chronic hepatitis $\mathrm{C}$ virus infection has been associated with liver iron loading. The cause of elevated serum iron indices in some HCV-infected individuals is not clear. The concomitant increase of serum AST and ALT levels suggests that iron and ferritin are released from damaged hepatocytes as a result of hepatic necroinflammation [35]. In addition, increased iron has been shown to enhance HCV replication in vitro [36]. 
In the current study, splenomegaly was observed in $96.9 \%$ of patients, whereas $90.73 \%$ of patients had hepatomegaly. The distribution of HCV, HBV, CMV, and HIV was studied by considering different clinical parameters related to thalassemia. In this study, we found that older age of the patients, longer duration of the disease in years, elevated liver enzymes $(\mathrm{U} / \mathrm{L})$, and increasing ferritin level $(\mathrm{ng} / \mathrm{mL})$ are associated with higher seroprevalence of TTIs. Similar findings were reported by other studies [37-39]. Though the standardized blood screening procedures were outlined in the 1990s for blood-related products and were subsequently implemented in various countries, higher prevalence of TTIs, especially $\mathrm{HCV}$, among thalassemic patients requires greater attention from a public health perspective. Screening of blood donors by advanced ELISA screening tests and RT-PCR could detect $\mathrm{HCV}$ in early stages of diseases and will provide better opportunities for risk assessment.

\section{Conclusion}

A total of 97 homozygous $\beta$-thalassemia patients were included in this study. The seroprevalence of HCV was the highest TTI in thalassemic children, with a lower percentage for HBV and CMV cases but there were no HIV cases. These seroprevalence-positive cases were significantly associated with older age, longer duration of diseases, increased liver enzymes, and higher ferritin levels. Recent solid-blood screening programs including advanced ELISA screening tests, liver enzymes, and RT-PCR will hopefully reduce the risk of TTIs associated with blood transfusions.

\section{Conflict of Interests}

The authors had no conflict of interests.

\section{Acknowledgment}

The authors thank proof-reading-services.com for linguistic editing.

\section{References}

[1] S. L. Thein, "Genetic modifiers of $\beta$-thalassemia," Haematologica, vol. 90, no. 5, pp. 649-660, 2005.

[2] S. H. Ansari, T. S. Shamsi, M. Ashraf et al., "Molecular epidemiology of $\beta$-thalassemia in Pakistan: far reaching implications," International Journal of Molecular Epidemiology and Genetics, vol. 2, no. 4, pp. 403-408, 2011.

[3] A. El-Beshlawy, N. Kaddah, A. Moustafa, G. Mouktar, and I. Youssry, "Screening for $\beta$-thalassaemia carriers in Egypt: significance of the osmotic fragility test," Eastern Mediterranean Health Journal, vol. 13, no. 4, pp. 780-786, 2007.

[4] S. L. Schrier, "Pathophysiology of thalassemia," Current Opinion in Hematology, vol. 9, no. 2, pp. 123-126, 2002.

[5] C. Skarmoutsou, I. Papassotiriou, J. Traeger-Synodinos et al., "Erythroid bone marrow activity and red cell hemoglobinization in iron-sufficient $\beta$-thalassemia heterozygotes as reflected by soluble transferrin receptor and reticulocyte hemoglobin content. Correlation with genotypes and HB A2 levels," Haematologica, vol. 88, no. 6, pp. 631-636, 2003.

[6] S. Aziz, J. Rajper, and W. Noorulain, "Treatment outcome of HCV infected paediatric patients and young adults at Karachi, Pakistan," Journal of Ayub Medical College, Abbottabad, vol. 24, no. 3-4, pp. 56-58, 2012.

[7] F. Said, A. E. Beshlawy, M. Hamdy et al., "Intrafamilial transmission of hepatitis C infection in Egyptian multitransfused thalassemia patients," Journal of Tropical Pediatrics, vol. 59, no. 4, pp. 309-313, 2013.

[8] E. Hussein, "Evaluation of infectious disease markers in multitransfused Egyptian children with thalassemia," Annals of Clinical and Laboratory Science, vol. 44, no. 1, pp. 62-66, 2014.

[9] A. A. Adly and F. S. Ebeid, "Cultural preferences and limited public resources influence the spectrum of thalassemia in Egypt," Journal of Pediatric Hematology/Oncology, vol. 37, no. 4, pp. 281-284, 2015.

[10] B. S. Buckner and E. B. Buckner, "Post-revolution Egypt: the Roy adaptation model in community," Nursing Science Quarterly, vol. 28, no. 4, pp. 300-307, 2015.

[11] C. Velati, L. Romanò, L. Fomiatti et al., "Impact of nucleic acid testing for hepatitis B virus, hepatitis $C$ virus, and human immunodeficiency virus on the safety of blood supply in Italy: a 6-year survey," Transfusion, vol. 48, no. 10, pp. 2205-2213, 2008.

[12] L. A. Quratul-Ain, M. Hassan, S. M. Rana, and F. Jabeen, "Prevalence of $\beta$-thalassemic patients associated with consanguinity and anti-HCV-antibody positivity-a cross sectional study," Pakistan Journal of Zoology, vol. 43, no. 1, pp. 29-36, 2011.

[13] A. H. Mollah, N. Nahar, A. Siddique, K. S. Anwar, T. Hassan, and G. Azam, "Common transfusion-transmitted infectious agents among thalassaemic children in Bangladesh," Journal of Health Population and Nutrition, vol. 21, no. 1, pp. 67-71, 2003.

[14] J. M. Barrera, B. Francis, G. Ercilla et al., "Improved detection of anti-HCV in post-transfusion hepatitis by a third-generation ELISA," Vox Sanguinis, vol. 68, no. 1, pp. 15-18, 1995.

[15] A. A. Adeyemi, O. A. Omolade, and R. R. Raheem-Ademola, "Immunochromatographic testing method for hepatitis B, C in blood donors," Journal of Antivirals \& Antiretrovirals, vol. 3, no. 10, pp. 4172-4175, 2013.

[16] H. Zaghloul and M. El-Shahat, "Recombinase polymerase amplification as a promising tool in hepatitis C virus diagnosis," World Journal of Hepatology, vol. 6, no. 12, pp. 916-922, 2014.

[17] E. Hussein, "Blood donor recruitment strategies and their impact on blood safety in Egypt," Transfusion and Apheresis Science, vol. 50, no. 1, pp. 63-67, 2014.

[18] J. G. Donahue, A. Muñoz, P. M. Ness et al., "The declining risk of post-transfusion hepatitis C virus infection," The New England Journal of Medicine, vol. 327, no. 6, pp. 369-373, 1992.

[19] K. Al-Naamani, I. Al-Zakwani, S. Al-Sinani, F. Wasim, and S. Daar, "Prevalence of hepatitis $\mathrm{C}$ among multi-transfused thalassaemic patients in Oman, single centre experience," Sultan Qaboos University Medical Journal, vol. 15, no. 1, pp. e46-e51, 2015.

[20] S. L. Stramer, S. A. Glynn, S. H. Kleinman et al., "National heart, lung, and blood institute nucleic acid test study group. Detection of HIV-1 and HCV infections among antibody negative blood donors by nucleic acid-amplification testing," The New England Journal of Medicine, vol. 351, no. 8, pp. 760$768,2004$.

[21] M. Al-Sheyyab, A. Batieha, and M. El-Khateeb, “The prevalence of hepatitis $B$, hepatitis $C$ and human immune deficiency 
virus markers in multi-transfused patients," Journal of Tropical Pediatrics, vol. 47, no. 4, pp. 239-242, 2001.

[22] M. Irshad and S. Peter, "Spectrum of viral hepatitis in thalassemic children receiving multiple blood transfusions," Indian Journal of Gastroenterology, vol. 21, no. 5, pp. 183-184, 2002.

[23] M. Rahman and Y. Lodhi, "Prospects and future of conservative management of beta thalassemia major in a developing country," Pakistan Journal of Medical Sciences, vol. 20, no. 2, pp. 105112,2004

[24] E. Angelucci, P. Muretto, A. Nicolucci et al., "Effects of iron overload and hepatitis $\mathrm{C}$ virus positivity in determining progression of liver fibrosis in thalassemia following bone marrow transplantation," Blood, vol. 100, no. 1, pp. 17-21, 2002.

[25] F. A. Ardalan, M. R. F. Osquei, M. N. Toosi, and G. Irvanloo, "Synergic effect of chronic hepatitis $\mathrm{C}$ infection and beta thalassemia major with marked hepatic iron overload on liver fibrosis: a retrospective cross-sectional study," BMC Gastroenterology, vol. 4, article 17, 2004.

[26] M. Zurlo, P. De Stefano, C. Borgna-Pignatti et al., "Survival and causes of death in thalassaemia major," The Lancet, vol. 334, no. 8653, pp. 27-30, 1989.

[27] R. N. Makroo, J. S. Arora, M. Chowdhry, A. Bhatia, U. K. Thakur, and A. Minimol, "Red cell alloimmunization and infectious marker status (human immunodeficiency virus, hepatitis B virus and hepatitis $C$ virus) in multiply transfused thalassemia patients of North India," Indian Journal of Pathology and Microbiology, vol. 56, no. 4, pp. 378-383, 2013.

[28] S. Mirmomen, S.-M. Alavian, B. Hajarizadeh et al., "Epidemiology of hepatitis B, hepatitis $\mathrm{C}$, and human immunodeficiency virus infections in patients with beta-thalassemia in Iran: a multicenter study," Archives of Iranian Medicine, vol. 9, no. 4, pp. 319-323, 2006.

[29] W. Antar, M. H. El-Shokry, W. A. Abd El Hamid, and M. F. Helmy, "Significance of detecting anti-HBc among Egyptian male blood donors negative for HBsAg," Transfusion Medicine, vol. 20, no. 6, pp. 409-413, 2010.

[30] Z. N. Said, M. H. El Sayed, I. I. Salama et al., "Occult hepatitis B virus infection among Egyptian blood donors," World Journal of Hepatology, vol. 5, no. 2, pp. 64-73, 2013.

[31] M. Altindis, I. Uslan, Z. Cetinkaya et al., "Investigation of hemodialysis patients in terms of the presence of occult hepatitis B," Mikrobiyoloji Bülteni, vol. 41, no. 2, pp. 227-233, 2007.

[32] R. Jamal, G. Fadzillah, S. Z. Zulkifli, and M. Yasmin, "Seroprevalence of hepatitis B, hepatitis C, CMV and HIV in multiply transfused thalassemia patients: results from a thalassemia day care center in Malaysia," Southeast Asian Journal of Tropical Medicine and Public Health, vol. 29, no. 4, pp. 792-804, 1998.

[33] D. Oraby, "Harm reduction approach in Egypt: the insight of injecting drug users," Harm Reduction Journal, vol. 10, article 17, 2013.

[34] S. Manisha, K. Sanjeev, N. Seema, C. Dilip, and D. Rashmi, "A cross-sectional study on burden of hepatitis C, hepatitis B, HIV and syphilis in multi-transfused thalassemia major patients reporting to a Government Hospital of Central India," Indian Journal of Hematology and Blood Transfusion, vol. 31, no. 3, pp. 367-373, 2015.

[35] J. E. Nelson and K. V. Kowdley, "Iron and hepatitis C," Current Hepatitis Reports, vol. 3, no. 4, pp. 140-147, 2004.

[36] S. Kakizaki, H. Takagi, N. Horiguchi et al., "Iron enhances hepatitis C virus replication in cultured human hepatocytes," Liver, vol. 20, no. 2, pp. 125-128, 2000.
[37] H. Hussain, R. Iqbal, M. H. Khan et al., "Prevalence of hepatitis $\mathrm{C}$ in $\beta$ thalassaemia major," Gomal Journal of Medical Sciences, vol. 6, no. 2, pp. 87-90, 2008.

[38] M. A. Shah, M. T. Khan, Z. Ullah, and Y. Ashfaq, "Prevalence of hepatitis B and C virus infection in multiple transfused thalassemic patients in North West Frontier Province," Pakistan Journal of Medical Sciences, vol. 21, no. 4, pp. 281-283, 2005.

[39] M. R. Uddin, M. Rana, M. Islam et al., "Seroprevalence of hepatitis C virus in thalassemic patients," Journal of Dhaka Medical College, vol. 18, no. 2, pp. 115-119, 2009. 


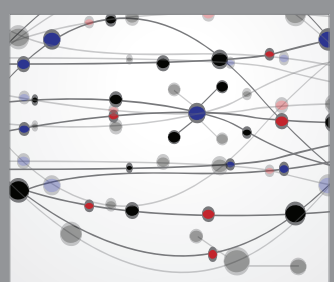

The Scientific World Journal
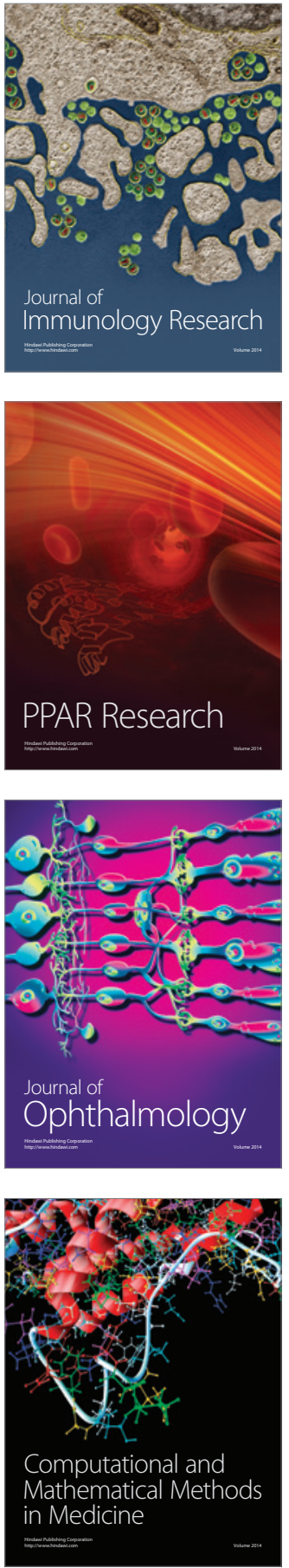

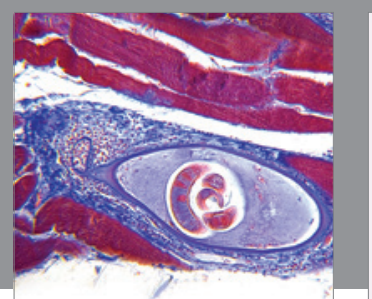

Gastroenterology Research and Practice

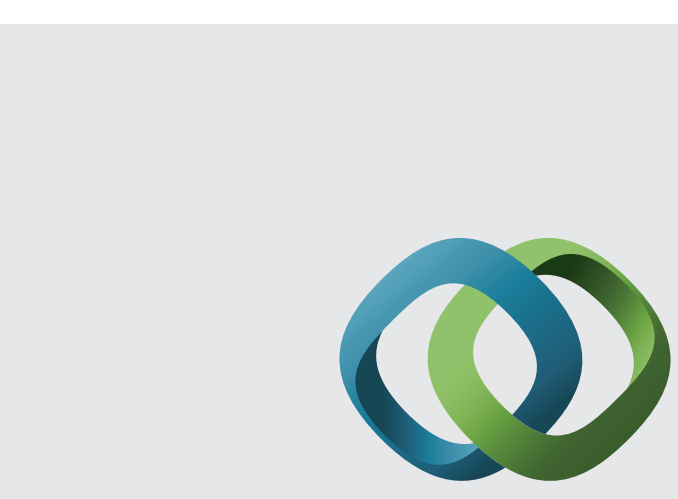

\section{Hindawi}

Submit your manuscripts at

http://www.hindawi.com
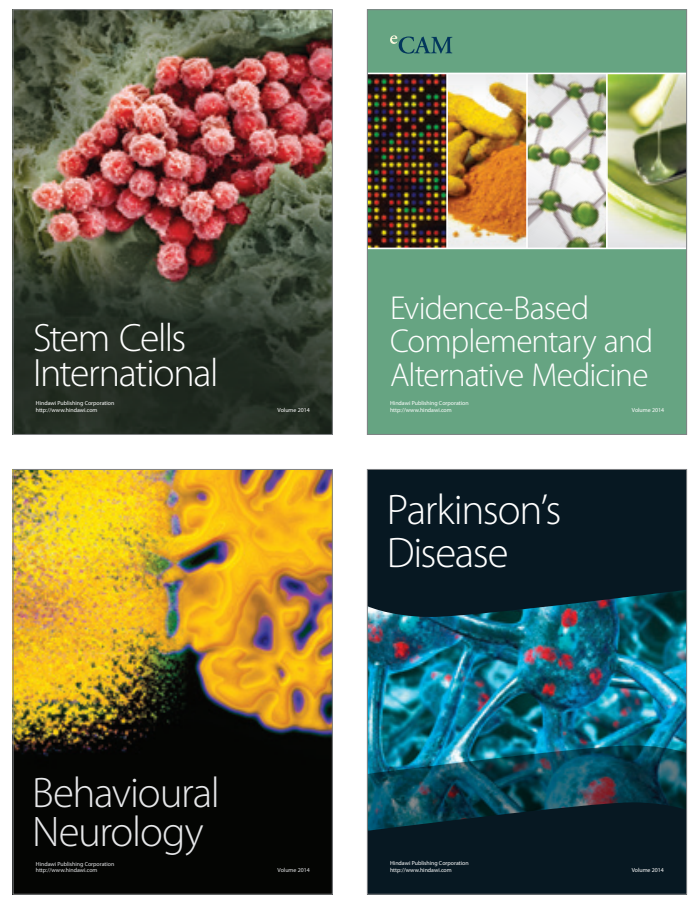
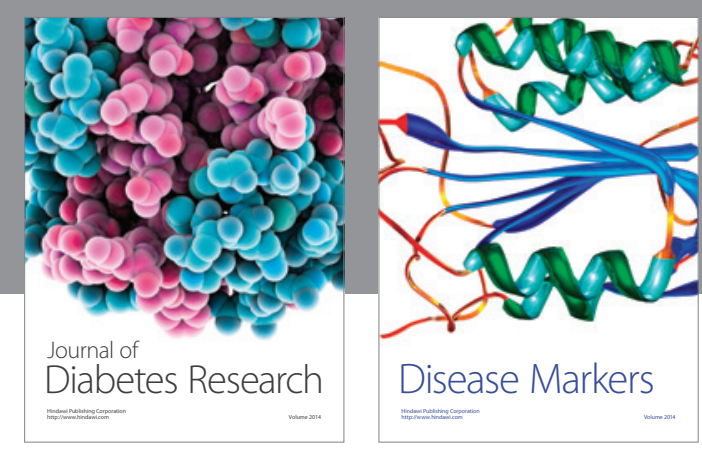

Disease Markers
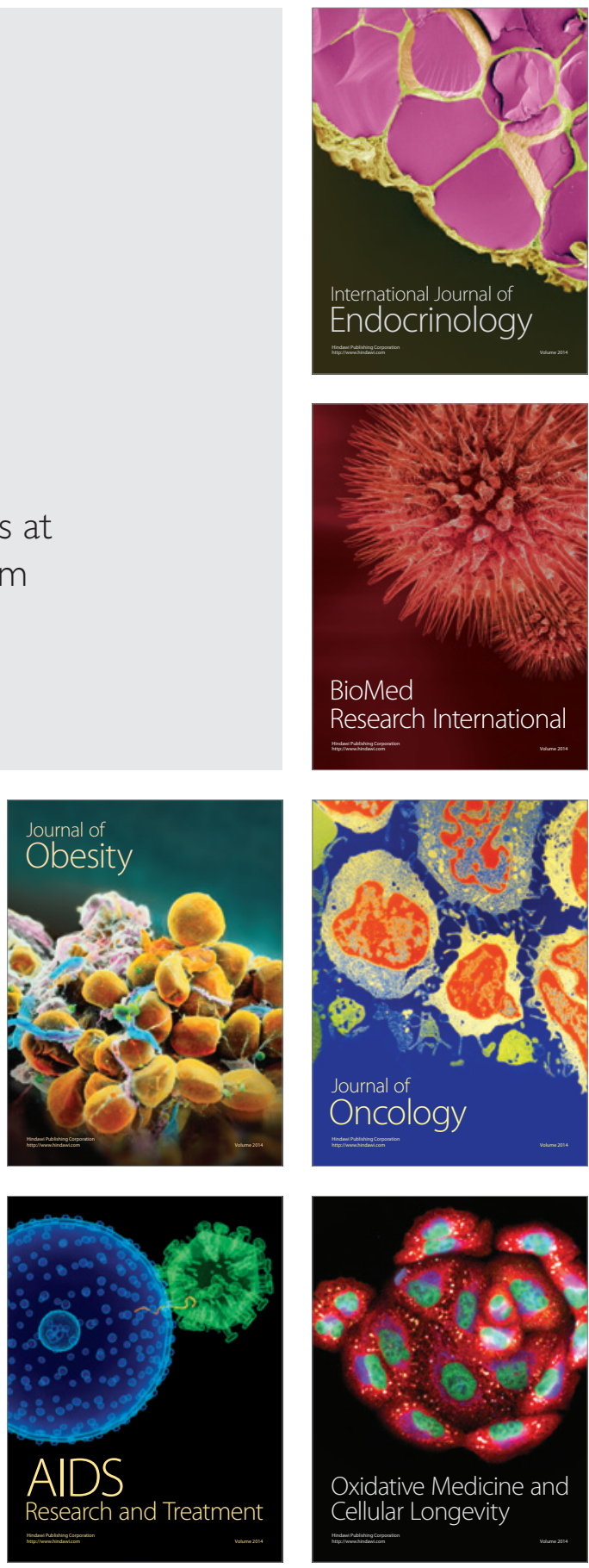